\section{MATHS FOR ENGINEERS}

Special Functions for Scientists and Engineers By W. W. Bell. Pp. xiv + 247. (Van Nostrand: Princeton, N.J., November 1968.) $30 s$ paper; $65 s$ boards.

THE description of natural phenomena often involves the use of sophisticated mathematics, but-in this country at any rate--the mathematical training imparted to physicists and engineers does not err on the side of robustness. A writer of a mathematical textbook designed for such readers thus finds himself in a dilemma: should he observe all the niceties of strict mathematical reasoning and risk blank incomprehension or, alternatively, should he shun the rigours of "real" mathematics and exhibit a largely formal development of the subject? The author of the book reviewed here has chosen the latter course and, in the present climate of the educational environment, it is difficult to cavil at his decision.

His object is to acquaint the reader with the principal properties of special functions (in particular those associated with the names of Legendre, Bessel, Hermite, Laguerre and Chebyshev) which constitute the small change of mathematical physics. He writes for readers whose knowledge of mathematics barely extends beyond the calculus and a nodding acquaintance with series, and consequently he has to skate lightly over questions involving the justification of infinite processes. As may be expected, the stress is predominantly on the formal side of the subject: the main concern is with identities and differential equations satisfied by special functions, with their orthogonality properties, and with generating functions. The text is confined to the mathematical theory; the author avoids, as a matter of policy, the treatment of physical applications. The arguments are deployed in considerable detail, and the presentation is easy to follow.

On its own ground, this is a nice, unpretentious and useful book. It is not outstanding, but it will give very considerable help to students and practitioners of physical science for whom mathematics is a daily, if not always a highly regarded, tool.

L. Mirsky

\section{GERMAN UNIVERSITIES}

\section{Guide to German Universities}

Compiled by Karl-Otto Saur. Part 1: Universities. Pp. xxx +666 . Part 2: Technische Hochschule. Pp. xxxiv + 667-1296. (Verlag Dokumentation: MünchenPullach. Distributed in the UK by CBD Research, Beckenham, Kent, 1967/1968.) 250s.

THese two volumes provide a compact and informative guide to German universities; their main value is likely to be the very comprehensive list of German professors which is included. General information about the universities is scantier--the guide makes no attempt to give details of courses, constitutions or administrative frameworks-but it is encouraging to find that the West German publisher has been open-minded enough to include information about the German Democratic Republic as well as the Federal Republic.

The guide comes in two volumes, bound in stout plastic. Volume one covers the universities of West and East Germany, with a list of all the universities in the world thrown in for good measure. Volume two does the same for the Technische Hochschule, and includes the complete index for both volumes. The index covers faculties, towns, and individuals, as well as a special index of institutes and professors. No academic staff apart from professors are mentioned. A final index, in English, is a list of disciplines, which enables the reader to locate all the departments in Germany interested in, say, Arabian philology.
Unfortunately, the layout of the volumes tends to confuse rather than illuminate. It compares poorly, for example, with the Commonwealth Universities Yearbook, another handbook which performs a similar function for univorsities in the British Commonwealth. Diligent indexsearching does enable this drawback to be overcome. It would also have been an enormous advantage to have some idea of the special interests of the professors listed, but this would doubtless have meant a much more bulky volume. It is hard to test the publisher's claim that the volume is up to date, but the intention is to issue a new edition in 1968. The same publisher is also intending to produce similar guides for the Austrian and Swiss universities.

\title{
Obituaries
}

\section{Professor W. M. Court Brown}

Professor W. M. Court Brown died on December 16, 1968 , at the age of 50 . He was director of the Medical Research Council Clinical and Population Cytogenetics Research Unit at the Western General Hospital, Edinburgh.

His early training was in radiotherapy and his first researches were concerned with elucidating the nature of radiation sickness. He then moved on from studying the more acute effects of radiotherapy to some of its possible long term consequences. He was the first to establish that radiotherapy as used for conditions such as ankylosing spondylitis could lead to the development of leukaemia. Subsequently with W. R. S. Doll, it was shown that the incidence of leukaemia was roughly proportional to the amount of radiation received by the bone marrow. They deduced a quantitative relationship between the dose of radiation and the risk of developing leukaemia that has been used internationally as a basis for deciding permissible levels of industrial and medical exposure.

Much of this work was done at the Postgraduate Medical School, London, where Court Brown was a member of the Medical Research Council staff. In 1956 he moved to Edinburgh and was appointed director of a newly formed Medical Research Council unit.

The late fifties saw the first reports of the new techniques which made the direct investigation of human chromosomes a practical possibility, and laid the foundations for the quite explosive developments in human cytogeneties which subsequently occurred. Court Brown immediatcly saw the possibilities opened up by these technical advances and he set about building up in his unit a research group to take advantage of them, not only in connexion with the investigations into the effects of radiation, but more widely. His unit has since established itself among the leading international research teams in human cytogenotics, and has made many important contributions. These include, among others, the first descriptions of the $X X Y$ and $X X X$ abnormalities in 1959; the demonstration in 1961 of the high incidence of sex ehromosome abnormalities among women with primary amenorrhoea; the demonstration in 1962 that radiationinduced chromosomal aberrations in circulating lymphocytes could be detected ten ycars or more after a single course of X-ray treatment; the finding in 1963 of consistent increases in the number of aneuploid cells in the older age groups, which differ in character in men and women; the discovery in $\mathbf{1 9 6 5}$ of the quite unusual incidence of $X Y Y$ males in maximum security institutions for people of particularly violent disposition; and the first systematic studies of the incidence of chromosomal aberrations 
of different types among randomly selected individuals in the general population.

Court Brown was among the first to appreciate the importance of applying the techniques for chromosome analysis to population surveys, and it is in this field that he made his own special contribution. He saw that it would be necessary to determine the incidence of chromosomal abnormalities both in the newborn and in the general adult population in order to assess the significance of the findings obtained in selected groups, such as the mentally retarded or disturbed, the congenitally handicapped, the infertile or groups of people persistently exposed to particular external hazards such as low doses of radiation. He also saw that the study of individuals with specific types of chromosomal aberration, ascertained through such population surveys, would open up new possibilities in medicine and in human genetics.

To translate these ideas into practice was a formidable undertaking, and it is a remarkable tribute to his powers as an organizer of such multidisciplinary research, and his insight into its fundamental significance, that so much was achieved in just a few years. A great deal has still to be published in detail, but the principal findings are presented and critically discussed in the short monograph Chromosome Studies in Adults (Cambridge University Press, 1966) and in a valuable review just published in the British Medical Bulletin (25, No. 1; 1969). His ideas on the medical and biological significance of the work are ably presented in his book Human Population Cytogenetics (North-Holland Press, 1967).

Court Brown was very conscious that the time consuming and laborious nature of chromosome analysis by direct microscopy imposed a severe restriction on the numbers of individuals who could be studied in such investigations. He concluded that the speed of advance would be much increased if computer aided techniques for the automatic counting and analysing of chromosomes in colls could be developed. With characteristic enthusiasm a great deal of his energy in the past three years was devoted to getting a research programme started in his unit to solve this problem. Much progress has already been made, and it is a tragedy that he will not be able to see it brought to fruition, or be able to take part in organizing the new and exciting epidemiological studies which its successful development should make feasible.

Human population cytogenetics, although a very recent field of study, has already been shown to have important implications both in medicine and in human biology. To Michael Court Brown must go much of the credit for the emergence of this new subject.

\section{Correspondence}

\section{Monsters by Sonar}

SiR,-My scientific complacency was utterly shattered by the nature and tone of your News and Views note entitled "Monsters by Sonar" (Nature, 220, 1272; 1968). I was particularly shocked by the way mud was thrown in the eyes of two reputable British scientists. The problem of the so-called Loch Ness monster is still a very real one and I was surprised that a famous scientific journal should be willing to dismiss the topic solely on the grounds of the armchair views of one man. Had your writer been given the opportunities that I have had to visit and study Loch Ness and also to interview some of the relatively few poople who have seen the so-called "monster", his opinion would probably not be so narrow minded.

There is a very definite problem which still defies a rational solution and it is in this context that Professor Tucker and Dr Braithwaite's results are particularly interesting. Of course sonar, like all electronics, is open to artefact; but Professor Tucker is presumably also aware of this. Admittedly their results would have been more valuable had calibrations been provided of the kind of reflexion which could be obtained from specified objects both animate and inanimate-at known ranges and depths; but this does not detract from the considered opinion of both Professor Tucker and Dr Braithwaite that they obtained evidence for some object or objects which moved both horizontally and vertically at speeds of up to 5-10 knots. Whatever the explanation of these particular recordings, they represent a sensible scientific approach to a very real problem and certainly do not merit the sneer with which they appear to have been greeted.

$$
\text { Yours faithfully, }
$$

Emmanuel College,

$$
\text { P. F. BAKER }
$$

Cambridge.

\section{Is Botany Dead?}

Sir,-In the light of recent correspondence in Nature, I cannot resist sending the enclosed letter which, if it does nothing else, will show the botanists that there is nothing new in the criticisms to which their branch of learning is now being subjected, and that the remedies now being suggested were also pointed out almost two centuries ago -by one whom we remember mostly as a zoologist:

The standing objection to botany has always been that it is a pursuit that amuses the fancy and exercises the memory, without improving the mind or advancing any real knowledge; and, where the science is carried no farther than a mere systematic classification, the charge is but too true. But the botanist that is desirous of wiping off this aspersion should be by no means content with a list of names; he should study plants philosophically, should investigate the laws of vegetation, should examine the powers and virtues of efficacious herbs, should promote their cultivation; and graft the gardener, the planter, and the husbandman, on the phytologist. Not that system is by any means to be thrown aside; without system the field of Nature would be a pathless wilderness; but system should be subservient to, not the main object of, pursuit.

[And so I could go on, but the rest of this letter, which I wrote to my friend Daines Barrington some time ago, is already in print for those who might wish to consult it ${ }^{1}$. I venture to think that it may be apposite to the discussion in which our botanical colleagues are currently engaged in the columns of your illustrious journal.]

$$
\begin{aligned}
& \text { Yours faithfully, } \\
& \text { Gilbert White, } \\
& \text { Selbourne, June 2nd, } 1778 .
\end{aligned}
$$
${ }^{1}$ The Natural History of Selborne 1789, and several subsequent
editions.

Yours faithfully,

Freshwater Biological Association,

G. Fryer

Windermere Laboratory,

Ambleside,

Westmorland. 